\title{
Impact of Cadmium Intoxication on Health Status, Rumen and Blood Constituents in Egyptian Ossimi Sheep
}

\author{
Oraby MI, Baraka TA and Rakha GH* \\ Department of Medicine and Infectious diseases, Faculty of Veterinary Medicine, Cairo University, Giza, Egypt \\ *Corresponding author: gamalrakha2030@gmail.com
}

Article History: 20-145 Received: 25-Jun-20 Revised: 08-Aug-20 Accepted: 18-Aug-20
A BS T RA C T
Toxic heavy metals particularly Cadmium (Cd) have a hazardous impact on animal health and productivity because of
their ill-degradability and bio-accumulation for long periods. This study carried out on 52 Ossimi sheep belonging to
Giza Governorate, including 12 sheep considered as control (kept in a private farm) and 40 sheep grazed on an area
polluted with cadmium. Drinking water, animal blood and rumen fluid samples were collected from all sheep. Complete
blood, rumen and serum constituents were analyzed. Iron, copper, zinc, oxidant, and antioxidant markers were evaluated
and Cd levels in water, rumen fluid and serum were investigated to show the impact of Cd on those parameters. Physical
examination revealed significant disturbance in health status of Cd-exposed sheep. Rumen fluid examination showed
significant increase in rumen pH, significant decrease in rumen ammonia-nitrogen, TVFAs, AST, ALT, GGT, Ca and
Ph. Blood constituent revealed significant alteration as significant decrease in RBCs count, Hb, PCV, MCHC and TLC
as well as impaired hepatic and renal function and significant decrease of antioxidant markers. These alterations
associated with strong positive correlation between these altered parameters and cadmium level in drinking water, rumen
fluid and blood samples which markedly increased more than permissible limits; these results should be put in
consideration in interpretation of affected animals' status and during treatment and control of cadmium exposed sheep
cases as well as consumption of such animals' meat and offal is not recommended.

Key words: Sheep, Cadmium, Blood, Rumen, Water, Antioxidants.

C2020 IJVS - All Rights Reserved

\section{INTRODUCTION}

Environmental pollution is a major conundrum facing animal industry and of all living organisms at different trophic and systematic levels (Ferrante et al. 2017). In recent years, water contamination by toxic heavy metals such as cadmium $(\mathrm{Cd})$ has accelerated dramatically due to natural and industrial sources (Masindi and Muedi 2018) and subsequently, these metals reach to plants and animals and dramatically affect human health through food chain (Miedico et al. 2016). Toxic heavy metals particularly Cd have a hazardous impact on animal health and productivity because of their ill-degradability and bioaccumulation for long periods (Milam et al. 2017; Morsy et al. 2020b).

Grazing sheep, the most abundant ruminant livestock species is one of agriculture pillars in Egypt as it can convert low-quality roughages into meat and milk for human consumption in addition to producing wool and hides (Morsy et al. 2020a). Water sources for grazing sheep are irrigation canals which contaminated with discharge of industrial, agricultural and municipal wastewaters which contain several types of hazards especially heavy metals such as lead, cadmium, nickel and mercury which are considered the most toxic for soil, plants and animals (Park and Shin 2006).

Cadmium released into the environment via the smelting of other metals, the burning of fossil fuels, the incineration of waste materials, and the use of phosphate and sewage sludge fertilizers (Bampidis et al. 2013). Entrance and absorption of $\mathrm{Cd}$ take place via skin, respiratory and alimentary routes (Godt et al. 2006). Cd exposure has been speculated to affect numerous body systems especially hepatobiliary and renal system (Gunnarsson et al. 2003) causing carcinogenicity, nephrotoxicity, osteoporosis, neurotoxicity, genotoxicity, teratogenicity and endocrine and reproductive effects (EFSA 2009). Cd was found to be antagonist with micronutrients especially copper, zinc and iron (NRC 2007) which are essential for all biochemical processes in the body, they are part of several enzymes, such as superoxide dismutase and glutathione peroxidase which are essential components of the antioxidant defense against oxidative stress by reactive oxygen species so protect tissues from damage (Evans and Halliwell 2001).

Cite This Article as: Oraby MI, Baraka TA and Rakha GH, 2021. Impact of cadmium intoxication on health status, rumen and blood constituents in Egyptian Ossimi sheep. International Journal of Veterinary Science 10(2): 102-106. https://doi.org/10.47278/journal.ijvs/2021.040 
Oxidative stress is the consequence of an imbalance between oxidants and antioxidants in which oxidant activity exceeds the neutralizing capacity of antioxidants (Lykkesfeldt and Svendsen 2007). Oxidative damage positively associated with cadmium level and occurs even at low levels of exposure to $\mathrm{Cd}$. Cd stimulate the production of free radical's reactive oxygen species (ROS) which in turn cause RBCs damage and lipid peroxidation (Ercal et al. 2001; Wang et al. 2014). Antioxidant-enzymatic and non-enzymatic-deployed in face of elevated lipid peroxidation activity to scavenge ROS to protect body cells (Celi 2011).

Studies on heavy metals pollution especially $\mathrm{Cd}$ were applied under experimental conditions (Stoev et al. 2003), and investigation of its effect on farm animals especially grazing sheep under natural practical condition rarely conducted (El-Sharkawy et al. 2008). Therefore, this study aimed to investigate the effect of water pollution with $\mathrm{Cd}$ on health status, rumen function, hematological parameters and serum constituents including hepatic, renal function tests and oxidant-antioxidant status of grazing sheep as well as correlation between $\mathrm{Cd}$ level and all parameters.

\section{MATERIALS AND METHODS}

\section{Ethical Approval}

The current study was approved by Veterinary Medicine Cairo University Institutional Animal Care and Use Committee, Faculty of Veterinary Medicine, Cairo University, Egypt (VET CU 160720202020).

\section{Animals and Clinical Examination}

In Giza Governorate, a total number of 52 Ossimi sheep aging between 3-5 years with average weight 35-45 $\mathrm{Kg}$ were divided into two groups: 12 sheep raised in nonpolluted grazing area (control group) and 40 sheep raised on grazing in rural polluted areas (exposed group). History of flocks concerning water sources, nutrition and management were recorded before the animals being clinically examined. All animals were subjected for careful clinical investigation including general body condition, inspection of visible mucous membranes of eye and examination of the skin and wool coat. Examination extended for other vital signs of health including pulse, respiratory rates, body temperature and examination of ruminal motility.

\section{Samples and Laboratory Investigations}

Blood samples were collected by puncture of jugular vein and divided into two portions. First portion collected on EDTA tubes for hematological examination including total erythrocytic count (RBCs), hemoglobin content ( $\mathrm{Hb}$ ), packed cell volume (PCV), mean corpuscular volume (MCV), mean corpuscular hemoglobin ( $\mathrm{MCH})$, mean corpuscular hemoglobin concentration (MCHC) and total leucocytic count (TLC) using automated hematology analyzer and the second portion collected in plain tubes for serum separation. Separated serum used for estimation of total protein, albumin, Aspartate Aminotransferase (AST), Alanine aminotransferase (ALT), Gamma Glutamyl Transpeptidase (GGT), Blood Urea Nitrogen (BUN), Creatinine, calcium $(\mathrm{Ca})$ and inorganic phosphorous using specific kits produced by SPECTRUM Co., Egypt, according to the method described by Young and Friedman (2001). Globulin, A/G ratio and BUN/Creatinine ratio were calculated. Rumen fluid samples were collected from each animal via stomach tube and suction pump; immediately examined for color, odor, consistency, $\mathrm{pH}$ and protozoal activity according to method described by Alonso (1979) Total volatile fatty acids (TVFAs) estimated by steam distillation method as described by Eadie et al. (1967). Rumen NH3-N was determined calorimetrically using specific kits produced by SPECTRUM Co., Egypt according to the method described by (Chaney and Marbach 1962). Activity of AST, ALT and GGT and levels of calcium and phosphorus were determined in clear supernatant after separation of rumen fluid according to Young and Friedman (2001) using specific kits produced by SPECTRUM Co., Egypt. Water samples $(50 \mathrm{ml})$ of drinking water were collected (six water samples from polluted area and one from non-polluted area). The technique of water sampling was conducted according to the recommendation of American Public Health Association (APHA 2012). Cd level was estimated in water, rumen fluid and blood samples by Flame Atomic Absorption Spectrometer (model SensAA, GBC, Australia) in Micro Analytical Center, Faculty of Science, Cairo University, Egypt. All glass tubes and plastic containers used in this study for mineral estimation were cleaned twice with diluted $\mathrm{HNO}_{3}$, then rinsed with deionized distilled water twice and then air-dried before using.

\section{Statistical Analysis}

Normality, mean values, standard errors (SE), Correlation coefficient and significance of correlation were calculated using (IBM SPSS Statistics for Windows, Version 20.0. IBM Corp, Armonk, NY). Independent samples T-test was applied to make comparison between the mean values of groups to check the significance. The results are represented as mean $\pm \mathrm{SE}$ and $\mathrm{P} \leq 0.05$ or $\mathrm{P} \leq 0.01$ was considered significant.

\section{RESULTS AND DISCUSSION}

Regarding history and clinical examination, the most obvious observations are depressed appetite, illthriftness, weakness, depression and rough wool. Disturbance in health status of these sheep in the form of emaciation, dullness, debility, and other anemic changes especially pale mucous membranes could be attributed to the high level of heavy metals especially $\mathrm{Cd}$. These findings agree with the findings of Bayoumi et al. (2013) and Oraby et al. (2015). Vital signs examination showed mild increase in respiratory rate which agreed with (Ali, 2005), moreover mild increase in pulse. Despite non-significant mild increase in respiratory and pulse rate, physical examination revealed normal $\mathrm{CH}$ sound of lung and normal heart beats (70-90/min). This may be attributed to normocytic normochromic anemia which reflected by significant decrease in RBCs count, $\mathrm{Hb}$ and PCV recorded in such animals. In spite of previous obtained data including decrease of body condition scores, pale mucous membrane, slight increase of pulse and respiratory rate that were recorded in grazed sheep, some owners neglect or give no attention to that changes in clinical signs specially it appears only with pushing sheep to walk or to run with 
Table 1: Hematological findings in control and exposed sheep and correlation with blood $\mathrm{Cd}$

\begin{tabular}{lccl}
\hline & Control sheep & Exposed sheep & Blood Cd \\
\hline RBCs $\left(\times 10^{6}\right)$ & $11.27 \pm 0.27$ & $9.82 \pm 0.06^{* *}$ & $-0.599^{* *}$ \\
PCV $(\%)$ & $28.83 \pm 0.90$ & $25.20 \pm 0.28^{*}$ & $-0.443^{*}$ \\
Hb $(\%)$ & $9.74 \pm 0.29$ & $8.18 \pm 0.06^{* *}$ & $-0.569^{* *}$ \\
MCV $(\mathrm{fl})$ & $25.70 \pm 0.87$ & $25.70 \pm 0.34$ & 0.028 \\
MCH $(p g)$ & $8.67 \pm 0.27$ & $8.34 \pm 0.09$ & -0.118 \\
MCHC $(\%)$ & $33.79 \pm 0.17$ & $32.61 \pm 0.42$ & -0.157 \\
TLC $\left(\times 10^{3}\right)$ & $7.25 \pm 0.17$ & $5.66 \pm 0.10^{* *}$ & $-0.634^{* *}$ \\
\hline
\end{tabular}

Values are expressed as mean \pm SE. $* \mathrm{P} \leq 0.05 ; * * \mathrm{P} \leq 0.01$.

Table 2: Rumen pH, TVFA, ammonia N, Ca, Phos and some enzymes in control and exposed sheep and correlation with rumen $\mathrm{Cd}$

\begin{tabular}{lccl}
\hline & Control & Exposed & Rumen Cd \\
\hline Rumen pH & $6.62 \pm 0.06$ & $7.08 \pm 0.02 *$ & $+0.697 *$ \\
TVFA & $56.60 \pm 0.36$ & $41.86 \pm 0.85^{* *}$ & $-0.763-* *$ \\
Ammonia N & $6.18 \pm 0.07$ & $5.12 \pm 0.12 * *$ & $-0.662 * *$ \\
AST (IU/L) & $0.24 \pm 0.01$ & $0.19 \pm 0.00^{*}$ & $-0.633^{* *}$ \\
ALT (IU/L) & $0.49 \pm 0.01$ & $0.41 \pm 0.00^{* *}$ & $-0.686^{* *}$ \\
GGT (IU/L) & $0.12 \pm 0.00$ & $0.10 \pm 0.00^{* *}$ & $-0.457 * *$ \\
Ca (mg/dl) & $1.45 \pm 0.04$ & $0.89 \pm 0.01 * *$ & $-0.884 * *$ \\
Phos (mg/dl) & $6.57 \pm 0.07$ & $4.98 \pm 0.07 * *$ & $-0.800^{* *}$ \\
\hline Values are exprese
\end{tabular}

Values are expressed as mean \pm SE. $* \mathrm{P} \leq 0.05 ; * * \mathrm{P} \leq 0.01$.

Table 3: Serum Proteins, enzymes, BUN, Creatinine, Ca and Phos in control and $\mathrm{Cd}$ exposed sheep and correlation with blood $\mathrm{Cd}$

\begin{tabular}{lccl}
\hline & Control sheep & Exposed sheep & Blood Cd \\
\hline Total Protein (g/dl) & $7.02 \pm 0.11$ & $5.86 \pm 0.07^{* *}$ & $-0.570^{* *}$ \\
Albumen (g/dl) & $3.40 \pm 0.06$ & $2.71 \pm 0.04^{* *}$ & $-0.675^{* *}$ \\
Globulin (g/dl) & $4.31 \pm 0.09$ & $3.15 \pm 0.08^{*}$ & -0.205 \\
A/G Ratio & $0.63 \pm 0.01$ & $0.89 \pm 0.03$ & -0.216 \\
AST (IU/L) & $68.92 \pm 1.39$ & $97.70 \pm 1.77^{* *}$ & $+0.682^{* *}$ \\
ALT(IU/L) & $23.81 \pm 0.73$ & $41.08 \pm 0.89^{* *}$ & $+0.693^{* *}$ \\
GGT(IU/L) & $37.48 \pm 2.09$ & $72.08 \pm 1.27^{* *}$ & $+0.763^{* *}$ \\
BUN (mg/dl) & $20.38 \pm 0.31$ & $35.27 \pm 0.44^{* *}+0.805^{* *}$ \\
Creatinine(mg/dl) & $0.68 \pm 0.03$ & $1.03 \pm 0.02^{* *}$ & $+0.590^{* *}$ \\
BUN / Creat. ratio & $30.34 \pm 1.26$ & $34.67 \pm 0.84$ & +0.395 \\
Ca (mg/dl) & $9.96 \pm 0.13$ & $7.76 \pm 0.06^{* *}$ & $-0.776^{* *}$ \\
Phos (mg/dl) & $6.14 \pm 0.12$ & $4.59 \pm 0.05^{* *}$ & $-0.710^{* *}$ \\
\hline Vas
\end{tabular}

Values are expressed as mean \pm SE. $* \mathrm{P} \leq 0.05$; $* \mathrm{P} \leq 0.01$.

Table 4: Trace elements, oxidant and antioxidants levels in both control and $\mathrm{Cd}$ exposed sheep and correlation with blood $\mathrm{Cd}$

\begin{tabular}{lccc}
\hline & $\begin{array}{c}\text { Control } \\
\text { sheep }\end{array}$ & Exposed sheep & Blood Cd \\
\hline Fe $(\mathrm{PPM})$ & $1.48 \pm 0.03$ & $0.54 \pm 0.05^{* *}$ & $-0.703^{* *}$ \\
$\mathrm{Zn}(\mathrm{PPM})$ & $0.86 \pm 0.01$ & $0.56 \pm 0.01^{* *}$ & $-0.720^{* *}$ \\
$\mathrm{Cu}(\mathrm{PPM})$ & $0.19 \pm 0.01$ & $0.10 \pm 0.00^{* *}$ & $-0.696^{* *}$ \\
$\mathrm{MDA}(\mathrm{nmol} / \mathrm{ml})$ & $0.46 \pm 0.01$ & $0.86 \pm 0.01^{* *}$ & $+0.720^{* *}$ \\
$\mathrm{SOD}(\mathrm{U} / \mathrm{ml})$ & $1.37 \pm 0.03$ & $0.89 \pm 0.02^{* *}$ & $-0.665^{* *}$ \\
$\mathrm{CAT}(\mathrm{U} / \mathrm{l})$ & $56.92 \pm 1.15$ & $37.88 \pm 0.64^{* *}$ & $-0.707^{* *}$ \\
$\mathrm{GSH}-\mathrm{PX}(\mathrm{mu} / \mathrm{ml})$ & $1.06 \pm 0.05$ & $0.37 \pm 0.01^{* *}$ & $-0.753^{* *}$ \\
Vitamin A $(\mu \mathrm{g} / \mathrm{dl})$ & $83.48 \pm 2.35$ & $60.11 \pm 0.93^{* *}$ & $-0.679^{* *}$ \\
Vitamin E $(\mu \mathrm{mol} / 1)$ & $24.92 \pm 0.85$ & $15.44 \pm 0.31^{* *}$ & $-0.786^{* *}$ \\
Vitamin C $(\mathrm{mg} / \mathrm{dl})$ & $1.07 \pm 0.07$ & $0.69 \pm 0.02^{* *}$ & $-0.606^{* *}$ \\
\hline Val
\end{tabular}

Values are expressed as mean \pm SE. $* * \mathrm{P} \leq 0.01$. PPM: part per million: MDA: Malondialdehyde: SOD: super oxide dismutase: CAT: catalase: GSH-PX: glutathione peroxidase.

effort. Owners when notice these signs kept the sheep in door and prevent them from grazing. Owners may be tried to treat these sheep while others get rid of them by selling or slaughtering. So, we could not obtain any sheep aged more than five years in this study.
Hematology showed significant decrease in RBCs count, $\mathrm{Hb}, \mathrm{PCV}, \mathrm{MCHC}$ and TLC, along with nonsignificant decrease in $\mathrm{MCV}$ and $\mathrm{MCH}$ in exposed group compared to control group, moreover, blood $\mathrm{Cd}$ concentrations recorded a significant negative correlation with RBCs count, $\mathrm{Hb}, \mathrm{PCV}$ and TLC as showed in Table 1. These findings agreed with the findings of Bayoumi et al. (2013) and Oraby et al. (2015).

Examination of rumen fluid revealed that physical characters were whitish green to brownish color according to type of ration, watery to sticky in consistency according to drinking state accompanied with aromatic to offensive odor. Also protozoa were microscopically low in number and motility in grazed sheep compared to control ones, this may indicate that a lower supply of cadmium for long period had a significant negative influence on the production of protozoa in the rumen leading to decrease in rumen contraction and consequently decrease in feed intake. These findings agreed with the findings of Sviatko and Zelenak (2000) and Oraby et al. (2015). Chemical examination of rumen fluid revealed significant increase in $\mathrm{pH}$ associated with significant decrease in ammonianitrogen, TVFAs, AST, ALT, GGT, Ca and Phos in exposed group compared to control group. These data confirmed by a significant negative correlation between rumen $\mathrm{Cd}$ and ammonia-nitrogen, TVFAs, AST, ALT, GGT, $\mathrm{Ca}$ and $\mathrm{Ph}$ and a significant positive correlation with $\mathrm{pH}$ as shown in Table 2. Significant decrease in rumen ammonia nitrogen in grazed sheep compared to control group may be attributed to decrease in urease activity due to high level of cadmium leading to reducing the rate of ammonia nitrogen release from dietary urea and this urea accumulated in the rumen and not converted to ammonia (Faixova et al. 2006; Oraby et al. 2015). Significant decrease in rumen TVFAs in grazed sheep compared to control group may be attributed to high level of $\mathrm{Cd}$ which cause damage to rumen microbiota and decrease fermentation, this prove decrease in energy intake leading to poor body condition scores, emaciation and weakness (Faix et al. 2005; Mousa 2014). Significant increase in ruminal $\mathrm{pH}$ of grazed sheep compared to control group may be attributed to decrease of volatile fatty acids, drinking drainage water which mainly of more alkaline $\mathrm{pH}$ or accumulation of urea in rumen due to inhibition of urease activity as recorded by Faixova et al. (2006). These results indicate that long term exposure to pollutants in drainage areas can alter the ruminal parameters of sheep and these finding agreed with the findings of Sviatko and Zelenák (2000). Published papers on effect of cadmium on rumen functions under natural conditions are very scare but presence of correlation between cadmium level and rumen parameters may suggest these all changes occurred.

Serum biochemical estimation showed significant decrease in total protein, albumin, globulin, calcium and inorganic phosphorus along with significant increase in AST, ALT, GGT, BUN and creatinine in exposed group compared to control. Furthermore, blood $\mathrm{Cd}$ was significantly correlated in a negative mode with serum total protein, albumin, globulin, calcium and inorganic phosphorus and a significant positive correlation with AST, ALT, GGT, BUN and creatinine (Table 3 ). These results agreed with findings published (Zaki and Mohamed 2012; Oraby et al. 2015). 
Int J Vet Sci, 2021, 10(2): 102-106.

Table 5: Cd level in drinking water, rumen fluid and blood of both control and Cd exposed sheep and its correlation with each other.

\begin{tabular}{lcccc}
\hline & Control sheep & Exposed sheep & Water Cd & $\mathrm{Rumen}$ Cd \\
\hline Water Cd (PPM) & $0.0026 \pm 0.0005$ & $0.304 \pm 0.041^{* *}$ & & \\
rumen Cd (PPM) & $0.02 \pm 0.00$ & $0.17 \pm 0.00^{* *}$ & $0.956^{* *}$ & \\
blood Cd (PPM) & $0.01 \pm 0.00$ & $0.12 \pm 0.01^{* *}$ & $0.877^{* *}$ & $0.771^{* *}$ \\
\hline
\end{tabular}
** $(\mathrm{P} \leq 0.01)$.

The most acceptable explanation to such increase in enzymatic activities could be attributed to the destructive effects of $\mathrm{Cd}$ on liver and kidney tissues and consequently liberating their intra cellular enzymes into the blood stream (Stoev et al. 2003). This confirmed by the strong positive correlations between blood Cd with serum AST, ALT and GGT.

The decrement in serum calcium and inorganic phosphorous could be attributed to the toxic effect of ingested $\mathrm{Cd}$ on the mucosal epithelial cell of gastrointestinal tract causing decrease of intestinal absorption of both calcium and phosphorous (AbdelAzeem and Hafez 2006).

Trace element status of grazing sheep showed a significant reduction in serum iron, copper and zinc compared to control group and these results could be owed to the competition of $\mathrm{Cd}$ with those biometals together with the reduction in appetite observed in exposed animals as showed in Table 4. These results agreed with the published literatures (El- Sharkawy et al. 2008; Bayoumi et al. 2013). The decrease in zinc level may be attributed to hypoproteinemia where most of plasma zinc is protein bound and this supported by the negative correlation recorded between serum copper, iron and zinc with blood $\mathrm{Cd}$. These results confirmed that study interaction of heavy metals with essential elements help to interpret the relation between heavy metals and the nutritional problems occur in the exposed animals. Thus, supplementation of copper, iron and zinc is essential in treatment and prevention of toxic effect of $\mathrm{Cd}$.

Oxidant status of grazing sheep showed significant increase in serum Malondialdehyde (MDA) levels which in accordance with those previously mentioned by Kanter et al. (2009) and Bayoumi et al. (2013). Such elevation could be attributed to lipid peroxidation caused by $\mathrm{Cd}$. The strong positive correlations between serum and MDA with blood $\mathrm{Cd}$ concentrations proved the fact that MDA is a marker for lipid peroxidation caused by $\mathrm{Cd}$ intoxication as recorded by Deger et al. (2009) and Crnogaj et al. (2010).

Antioxidant parameters showed significant increase in significant decrease in SOD, CAT, GSH-Px, Vit. A, Vit. E and Vit. $\mathrm{C}$ in exposed group compared to control. And also blood $\mathrm{Cd}$ concentrations recorded a significant negative correlation with SOD, CAT, GSH-Px, Vit. A, Vit. E and Vit. $\mathrm{C}$ as showed in Table 4 . The obtained results agreed with those recorded by Ercal et al. (2001), Ali (2005), Bayoumi et al. (2013) and Abdel-Saeed and Salem (2019).

$\mathrm{Cd}$ level estimation showed significant increase of $\mathrm{Cd}$ in polluted water, rumen fluid and blood in exposed sheep compared with control group and a significant positive correlation between $\mathrm{Cd}$ level in water, rumen and serum (Table 5).

Polluted water revealed significant increase in $\mathrm{Cd}$ concentrations which exceed the corresponding values in water collected from non-polluted water and exceed the recommended permissible limits recorded by WHO
(2004). The obtained results were in accordance the findings those reported by Ali (2005), Bayoumi et al. (2013) and Oraby et al. (2015). The high concentrations of $\mathrm{Cd}$ in drainage water could be attributed mostly to the high level of pollution from continuous discharge of sewage, industrial and agriculture effluents. Agricultural wastes include a wide range of organic materials (often containing pesticides), animal wastes, sewage sludge, and phosphate fertilizer beside industrial wastes and its contents from heavy metals. This high-risk value indicated that many notices, awareness, laws, information and impressive attention should be taken to use this drainage water to plant irrigation or animal drinking rather than for human consumption.

Significant increase in ruminal cadmium level in grazed sheep compared to control group nearly agreed with the findings of Faix et al. (2005), who recorded high Cd level in rumen wall of grazed sheep and (Oraby et al. 2015). Mean values of blood $\mathrm{Cd}$ concentrations showed significant increase in exposed sheep compared to control group. Our results agreed with those recorded by Zaki and Mohamed (2012) and Bayoumi et al. (2013).

\section{Conclusion}

Exposure of sheep to cadmium pollutant has adverse effect on body condition scores, rumen functions, liver and kidney functions; reduction in antioxidants activity which enhances occurrence of infectious and non-infectious diseases. Significant alterations and correlations were detected in this study; these results should be put in consideration in interpretation of affected animals' status and during treatment and control of $\mathrm{Cd}$ exposed sheep cases.

\section{REFERENCES}

Abdel-Azeem AM and Hafez MA, 2006. Studies on the environmental pollution with lead and cadmium and its effect on Egyptian buffaloes in Sharkia Government. Kafr El Sheikh Veterinary Medical Journal 4: 79-195.

Abdel-Saeed H and Salem NY, 2019. Evaluation of total antioxidant capacity, malondialdehyde, catalase, proteins, zinc, copper and IgE response in ovine verminous pneumonia. International Journal of Veterinary Science 8: 255-258.

Ali AE, 2005. Residual effect of heavy metals due to used drinking water polluted with sewage on health performance and blood serum antioxidant vitamins in sheep and goats in Assiut governorate. Assiut University Bulletin for Environmental Research Journal 8: 41-50.

Alonso A, 1979. Diagnostic analysis of rumen fluid. The Vet Clin North America. Large Animal Practice 1: 363-376.

APHA, 2012. Standard methods for the examination of water and wastewater. $22^{\text {nd }}$ Ed. Washington, DC, USA.

Badiei KN, 2009. Effect of cadmium on thyroid function in sheep. Comparative Clinical Pathology 18: 255-259.

Bampidis VA, Nistor E, Nitas D 2013. Arsenic, cadmium, lead and mercury as undesirable substances in animal feeds. Animal Science and Biotechnologies 46: 17-22. https://doi.org/10.1080/19440049.2017.1300686 
Bayoumi YH, El Kabbany AM, El Maghawry S and Attia H, 2013. Assessment of the impact of environmental pollution with heavy metals on sheep reared at Bahr El Bakar region. Ph. D. Faculty Vet. Med. Zagazig Univ. Egypt, pp: 208

Celi P, 2011. Biomarkers of oxidative stress in ruminant medicine. Immunopharmacology and Immunotoxicology 33: 233-240. https://doi.org/10.3109/08923973.2010.514917

Chaney AL and Marbach EP, 1962. Modified reagents for determination of urea and ammonia. Clinical Chemistry Journal 8: 130-132.

Crnogaj M, Petlevski R, Mrljk V, Kis I, Torti M, Kucer N, Matijatko V, Sacer I and Stokovic I, 2010. Malondialdehyde levels in serum of dogs infected with Babesia canis. Veterinary Medicine 55: 163-171.

Deger S, Deger Y, Bicek K, Ozdal N and Gul A, 2009. Status of lipid peroxidation, antioxidant and oxidation products of nitric oxide equine babesiosis: status of antioxidant and oxidant in equine babesiosis. Equine Veterinary Science 29: 743-747. https://doi.org/10.1016/j.jevs.2009.07.014

Eadie JM, Hobson P and Mann S, 1967. A note on some comparisons between the rumen content of barley-fed steers and that of young calves also fed on a high concentrate ration. Animal Science Journal 9: 247-250.

El-Sharkawy EE, El- Kattan YA, Senousi SA and Saleh MA, 2008. The relation between heavy metals and trace elements levels in blood of sheep reared on sewage-polluted plants. Assuit Veterinary Medical Journal 17: 156-168.

Ercal N, Orhan GH and Burns KN, 2001. Toxic metals and oxidative stress. Part 1. Mechanisms involved in metalinduced oxidative damage. Current Topic in Medicinal Chemistry 1: 529-539.

EFSA, 2009. European Food Safety Authority (EFSA). Cadmium in food - scientific opinion of the panel on contaminants in the food chain. EFSA Journal 980: 1-139. https://doi.org/ 10.2903/j.efsa.2009.980

Evans P and Halliwell B, 2001. Micronutrients: Oxidant/ antioxidant status. British Journal of Nutrition 85: 67-74.

Faix S, Faixova Z, Boldizarova K and Javorsky P, 2005. The effect of long-term high heavy metal intake on lipid peroxidation of gastrointestinal tissue in sheep. Veterinary Medical Czech 50: 401-405.

Faixová Z, Faix Š, Maková Z, Vaczi P and Prosbová M, 2006. Effect of divalent ions on ruminal enzyme activities in sheep. Acta Veterinaria 56: 17-23.

Ferrante M, Pappalardo AM, Ferrito V, Pulvirenti V, Fruciano C, Grasso A, Sciacca S, Tigano C and Copat C, 2017. Bioaccumulation of metals and biomarkers of environmental stress in parablennius sanguinolentus (pallas, 1814) sampled along the Italian coast. Marine Pollution Bulletin 122: 288296. https://doi.org/10.1016/j.marpolbul.2017.06.060.

Godt J, Scheidig F, Grosse-Siestrup C, Esche V, Brandenburg P, Reich A and Groneberg DA, 2006. The toxicity of cadmium and resulting hazards for human health. Journal of Occupational Medicine and Toxicology 1: 1-6

Gunnarsson D, Nordberg G, Lundgren P, Selstam G, 2003. Cadmium-induced decrement of the $\mathrm{LH}$ receptor expression and CAMP levels in the testis of rats. Toxicology 183: 5763. https://doi.org10.1016/s0300-483x(02)00440-7

Kanter M, Aksu B, Akpolat M, Tarladacalisir YT, Aktas C and Uysal H, 2009. Vitamin E protects against oxidative Damage caused by cadmium in the blood of rats. European Journal of General Medicine 6: 154-160.

Lykkesfeldt J and Svendsen O, 2007. Oxidants and antioxidants in disease: Oxidative stress in farm animals. The Veterinary Journal 173: 502-511. https://doi.org/10.1016/j.tvjl.2006.06. 005

Morsy M, El-Ghannam A, El-Rehim AY, Saleh S and Arafa M, 2020a. Assessing of heavy metals in serum of Barki sheep in rainfed area at Matrouh governorate. Journal of Veterinary Medical Research 27: 5-17.

Morsy MM, El-Ghannam AA, Saleh SY, 2020b. Assessment of serum mineral concentrations of barki sheep and its impact on kidney functions in El-Hammam city. Advancement in Animal and Veterinary Science 8(s1): 68-75.

Masindi V and Muedi KL, 2018. Environmental contamination by heavy metals. Heavy Metals; Intech Open: Aglan, France, pp: 115-133.

Miedico O, Iammarino M, Paglia G, Tarallo M, Mangiacotti M and Chiaravalle AE, 2016. Environmental monitoring of the area surrounding oil wells in val d'agri Italy): Element accumulation in bovine and ovine organs. Environmental Monitoring and Assessment 188: 338. https://doi.org/ 10.1007/s10661-016-5317-0

Milam C, One B, Dogara K and dan Yila Y, 2017. Assessment of heavy metals (as, cd, cr, cu, ni, pb and zn) in blood samples of sheep and rabbits from Jimeta-yola, Adamawa state, Nigeria. International Journal of Advances in Pharmacy, Biology and Chemistry 6: 160-166.

Mousa SA, 2014. Influence of in vitro addition of metal ions salts on rumen fermentation parameters and selected ruminal enzymes activity in sheep and goats. Life Science Journal 11 198-203.

NRC, 2007. Nutrient Requirements of Small Ruminants: Sheep, goats, cervids and New World camelids. National Academy Press, Washington, DC.

Nie NH, Bent DH and Hull CH, 1975. SPSS: Statistical Package for the Social Sciences, McGraw-Hill, New York, pp: 362.

Oraby MI, Rakha GH, Elsayed AA, 2015. Some Studies on Effect of Drainage Water on Sheep Health. M.Sc. Thesis, Fac. Vet. Med., Cairo University, Egypt, pp: 77.

Stoev SD, Grozeva N, Simeonov R, Borisov I, Hubenov H, Nikolov Y, Tsaneva M and Lazarova S, 2003. Experimental cadmium poisoning in sheep. Experimental Toxicology and Pathology 55: 309-314. https://doi.org/10.1078/0940-299300333

Sviatko P and Zeleňák I, 2000. Effect of cadmium on the rumen protozoan population in sheep. Veterinary Medical Czech, 45: 343-346.

Wang J, Zhu H, Liu X, Liu Z, 2014. Oxidative stress and Ca (2+) signals involved on cadmium-induced apoptosis in rat hepatocyte. Biological Trace Element Research 161: 180-9. https://doi.org/10.1007/s12011-014-0105-6

WHO, 2004. Guidelines for Drinking Water Quality. 3rd Ed. Vol. 1 Recommendation, Geneva, pp: 515.

Young DS and Friedman RB, 2001. Effects of Disease on Clinical Laboratory Tests. 4th Ed., Washington. DC: AACC Press, pp: 345.

Zaki MS and Mohamed MI, 2012. Some studies in Baraki sheep intoxicated with cadmium. Life Science Journal 9: 786-790. 